https://doi.org/10.24201/aap.2021.317

ARTÍCULO

\title{
¿Quién se excusa? La covid-19 como área de conflictividad entre Estados Unidos y la República Popular China en 2020
}

\section{Who Excuses Himself? Covid-19 as an Area of Conflict Between the United States and the People's Republic of China in 2020}

\author{
ABRAHAM NAVARRO GARCÍA \\ https://orcid.org/0000-0003-4502-4228
}

Universidad Autónoma de Baja California, México

Recepción: 1 de octubre de 2020 Aceptación: 2 de noviembre de 2020

Resumen: El presente escrito estudia las tensiones entre los gobiernos de Estados Unidos y la República Popular China en torno a la pandemia de covid-19 en 2020, argumentando que el gobierno de Trump abandonó sus compromisos de gran potencia en materia de salud al poner el acento en el conflicto con China, país que, en contraste, deja ver una vocación global que le permitirá avanzar en su posicionamiento dentro de la arquitectura de gobernanza global aún vigente. Sin embargo, no es esperable que China llene el vacío dejado por Estados Unidos de forma satisfactoria en el corto plazo; la cooperación entre los actores más relevantes del sistema internacional es indispensable para superar la crisis.

Palabras clave: covid-19; pandemia; Estados Unidos; China; salud.

\begin{abstract}
This paper examines the tensions between the governments of the United States and the People's Republic of China concerning the Covid-19 pandemic in 2020. It argues that the Trump administration abandoned the health commitments of a grand power to emphasize conflict with China, a country attempting to improve its relative position in the
\end{abstract}


current global governance regime. Nevertheless, it is not reasonable to expect China to satisfactorily fulfill the vacuum left by the United States in the short term; therefore, the collaboration between the most prominent actors in the international system is still needed to overcome the crisis.

Keywords: Covid-19; pandemic; USA; China; health.

La Asamblea General de las Naciones Unidas del 21 de septiembre de 2020 tuvo un carácter conmemorativo por el septuagésimo quinto aniversario del organismo internacional, el cual adoptó para la ocasión el lema "El futuro que queremos, las Naciones Unidas que necesitamos: reafirmando nuestro compromiso colectivo con el multilateralismo". Lamentablemente, durante el evento, el presidente estadunidense, Donald Trump, culpó a China de la propagación del SARS-CoV-2 e hizo un llamado para que "rindiera cuentas". El presidente chino, Xi Jinping, no dejó pasar la ocasión y replicó que su país no tenía “intención de entrar en una guerra fría con ningún país” (BBC 2020a). Éste es uno de los tantos episodios que han dado continuidad al caudal de reproches entre ambos países acerca de su manejo de la pandemia. La propagación de la enfermedad pandémica comenzó en un momento de auge de los nacionalismos poco propicio para la cooperación, como lo ilustra el momento descrito. De hecho, la propia crisis parece estar amplificando las motivaciones nacionalistas entre los actores más relevantes de la arquitectura institucional de la gobernanza global de la salud.

El presente escrito analiza las tensiones entre los gobiernos de Estados Unidos y China en torno a la pandemia, sosteniendo que la retracción de la administración de Trump de la perspectiva comprehensiva de gran potencia en materia de salud tuvo como eje el conflicto con China, país que muestra una perspectiva de proyección global en su diplomacia de salud y está ganando cierto terreno en un momento en que la cooperación internacional es urgente para superar la crisis de la covid-19. El análisis propuesto comienza con una reflexión sucinta sobre el carácter multisistémico de la pandemia. La segunda parte plantea una perspectiva de clasificación estatal. La tercera sección estudia el proceso de retracción de la perspectiva comprehensiva estadunidense de gran potencia a través del énfasis de la administración Trump en el conflicto con China. La cuarta sección considera la perspectiva del gobierno de China sobre ese reclamo y sus argumentos para procurar proyección global. 


\section{LA PANDEMIA COMO CAMBIO DE LARGA DURACIÓN}

A finales de 2019, una cepa de coronavirus altamente contagiosa y patogénica, clínicamente multisistémica y preponderantemente respiratoria, de transmisión por secreciones respiratorias, comenzó a propagarse en la ciudad de Wuhan, en China. La movilidad poblacional relacionada con el festival de primavera contribuyó a que el virus se expandiera a todas las provincias de ese país y en países circundantes como Japón y Corea del Sur cuando terminaba enero. E1 30 de ese mes, la Organización Mundial de la Salud (OMS) declaró a la epidemia una Emergencia Pública de Importancia Internacional. Al momento de escribir estas líneas, el número de casos confirmados a nivel mundial rebasa los 77 millones y el número de defunciones no está lejos de llegar a los dos millones, cifras que muy probablemente subrepresentan el impacto real de la pandemia por las dificultades en los sistemas de detección, diagnóstico y registro en el mundo, y por la variación sintomática de los infectados, que incluye sectores asintomáticos pero igualmente contagiosos. Por si esto no fuera suficiente, hay una proporción de pacientes que están experimentando efectos crónicos que comprometen seriamente su calidad de vida.

El virus ha sumido a la mayoría de los países del orbe en esquemas de aplicación de medidas de aislamiento social que, a su vez, han propiciado la desaceleración económica global más profunda desde la Gran Depresión, con una pérdida estimada para 2020 de $-5.2 \%$ del PIB global, $-7 \%$ del PIB de las economías avanzadas y $-2.5 \%$ del de las subdesarrolladas (Hall-Smith 2020). El mundo experimenta ahora los efectos de las segundas olas y hay preocupación por la convergencia de la enfermedad emergente con la influenza estacional. A las afectaciones directas en los sistemas de salud -entre ellas la disrupción del seguimiento de pacientes con condiciones crónicas - hay que añadir el riesgo que la pandemia entraña para el cumplimiento del tercer objetivo de la agenda 2030 de Naciones Unidas, salud para todos. La pandemia está afectando las campañas de vacunación, así como la provisión de servicios enfocados en la disminución de la mortalidad infantil, la incidencia del VIH/sida y la mortalidad por malaria y tuberculosis - entre 2020 y 2025 podría haber 6.5 millones de casos adicionales de esta última enfermedad como resultado directo de la disrupción del diagnóstico y tratamiento (Stop TB Partnership 2020). 
La revisión de las repercusiones de la pandemia en otros objetivos también es alarmante. El primero de ellos, la no pobreza, se dificulta con la estimación de los 500 millones de pobres que podría dejar la pandemia (Redacción AN / ES 2020). En términos de la reducción del hambre, la covid-19 ha agudizado las deficiencias en las cadenas globales de suministro de alimento para países frágiles. En lo que toca al objetivo de trabajo decente, la enfermedad ha provocado la pérdida de al menos $16 \%$ de los empleos entre los jóvenes en el mundo. Respecto a la igualdad de género, la pandemia ha agravado el problema de la violencia en contra de las mujeres dentro del seno familiar. En materia educativa, la crisis ha evidenciado la brecha digital (Programa de Naciones Unidas para el Desarrollo s. f.). La pandemia también ha motivado un debate normativo sobre la pertinencia del mantenimiento de sanciones económicas en países en desarrollo, evidentemente más vulnerables a la crisis sanitaria (Noroozi 2020).

Las implicaciones políticas de la pandemia también son materia de reflexión. En el corto plazo, elecciones y referendos han sido pospuestos, mientras que los gobiernos tienen dificultades para garantizar la oferta de servicios mediante procedimientos digitales (Programa de Naciones Unidas para el Desarrollo s. f.). En muchos países, los gobernantes enfrentan una presión no conocida en generaciones respecto a la medición de su eficacia en función de la calidad de su respuesta a una crisis específica entre sus ciudadanos y partidos y grupos de oposición. Esta presión ha hecho que la salud pública se posicione como una prioridad en la agenda política de varios países, en primera instancia con respecto a los niveles de insumos necesarios para hacer frente a la emergencia - incluidas las vacunas-; en el mediano plazo, la pandemia está propiciando una mayor reflexión sobre las condiciones crónicas y no comunicables que predisponen a las poblaciones a una mayor morbilidad y mortalidad debido a la enfermedad por coronavirus. Los gobiernos también encaran la toma de decisiones en entornos complejos en los que se puede presentar la aparente disyuntiva entre salvar vidas o salvar la economía. Además, la pandemia fue un factor decisivo de desgaste para la presidencia de Donald Trump que contribuyó al triunfo de Joe Biden en las apretadas elecciones presidenciales de noviembre de 2020.

A nivel internacional, la pandemia ha hecho surgir diferencias entre países debido a la aparición de medidas sanitarias que se perciben contrarias a los intereses de alguno de 
ellos, como lo hace ver el reclamo del primer ministro portugués, António Costa, al gobierno de Reino Unido por la cuarentena impuesta a los viajeros procedentes de su país (Agencia EFE 2020). La pandemia también ha sido causa de conflicto entre países con roces previos, caso que se ilustra bien con el reclamo de "transparencia" hecho por Estados Unidos a Venezuela, Nicaragua y Cuba sobre las medidas represivas que pueden afectar la provisión de servicios médicos en esos países (Belchi 2020).

Respecto a las repercusiones políticas de la pandemia en el largo plazo, destaca la disyuntiva que algunos analistas han planteado en los últimos meses sobre las actitudes y valores que definirán el manejo de la crisis. Yuval Harari plantea que la pandemia puede reforzar la vigilancia totalitaria, justificada en la necesidad de seguridad biológica o el empoderamiento de los ciudadanos. (Anónimo 2020). Por su parte, Byung-Chul Han resalta la mejor capacidad de los Estados autoritarios para responder a las emergencias sanitarias y que China se encuentra en una circunstancia de ventaja para promover su modelo de desarrollo autoritario (2020). En otros términos, la vulnerabilidad de los individuos puede hacerlos proclives a depositar mayor confianza en el Estado, y sus representantes en turno podrían abusar de sus atribuciones. Slavoj Žižek observa que la pandemia ha revelado la necesidad de coordinación de los mercados y de limitación del poder de los Estados nacionales. También aprecia un conflicto entre la "barbarie", donde prevalece el más fuerte, y la solidaridad y cooperación entre los pueblos. Žižek incluso ha llegado a señalar que la pandemia asestará un "golpe mortal al capitalismo" (Gómez 2020). Un sentido diferente de la crisis es compartido por Noah Chomsky, pues la crisis sanitaria evidencia otro fallo “"colosal' del neoliberalismo" (Magdaleno 2020). Crisis Group, a su vez, ha sugerido otras dos perspectivas encontradas que han prevalecido: por un lado, la comprensión de que la cooperación es la mejor opción para mitigar los efectos del virus; por el otro, el aislamiento como mejor alternativa para la propia protección (Wintour 2020). Estas ideas son un muestrario de los debates respecto al legado transversal y negativo del neoliberalismo para las poblaciones mayoritarias de los países industrializados y en desarrollo.

La magnitud histórica de la crisis abarca muchos otros aspectos que no es posible detallar en este espacio; baste simplemente mencionarlos: vida cotidiana, patrones de consumo, formas de convivencia, dinámicas laborales, identidades y sicología social de todas 
las comunidades afectadas. La crisis de la covid-19 no es sólo multisistémica en un sentido clínico, sino sociológico también. Es decir, es un "hecho social total" que trastorna relaciones sociales, actores, instituciones y valores (Martínez 2020).

\section{ASIMETRÍA SISTÉMICA: POTENCIAS MUNDIALES Y REGIONALES}

La noción de superpotencia y potencia regional adoptada en este estudio toma en cuenta la clasificación de los Estados propuesta por Alberto Rocha y Daniel E. Morales. El poder, un concepto central en el presente análisis, puede entenderse, en los términos de Joseph Nye, como la habilidad de conseguir nuestros propósitos por medio de la modificación del comportamiento de los demás, objetivo que se logra mediante capacidades de orden económico y militar (poder duro) o por vía de recursos inmateriales que proceden de la cultura y la política (poder blando) (Nye 2002). Según Rocha y Morales, el sistema político internacional está jerarquizado. Las potencias mundiales se encuentran en el centro del sistema capitalista y en la cima de la jerarquía; las potencias medias se sitúan también en el centro, aunque por debajo de las potencias mundiales, mientras las potencias regionales yacen en la semiperiferia y en un tercer nivel de la jerarquía mundial (2014).

La posición precisa de los Estados puede estimarse mediante tres índices generales que corresponden al poder mundial, a la calidad institucional y a su nivel de globalización. Las potencias mundiales, entre las que figura Estados Unidos como superpotencia, también se caracterizan por conservar una dirección autónoma efectiva de sus asuntos internos y externos. Ejercen acción política sobre sus aliados y tienen oportunidad de marcar su línea de acción en foros y organismos especializados como el G-7, el Fondo Monetario Internacional, el Banco Mundial y la Organización Mundial de Comercio. La función básica de una potencia mundial es dirigir el sistema político internacional (Rocha y Morales 2014).

Las potencias regionales se encuentran en el área del capitalismo semidesarrollado, la semiperiferia. Estructuralmente se sitúan entre las potencias mundiales y los Estados menores o periféricos. Cuentan con capacidades materiales significativas mientras que las de carácter inmaterial son limitadas. Sus procesos modernizadores y democratizadores, aunque menos intensos que en las potencias mundiales y medias, están en consolidación. Estos 
actores regionales procuran su ascenso en la región y a nivel sistémico (el listado de Rocha y Morales considera a China, India, Brasil, Rusia y Malasia, entre otros países), por lo que tienden a cuestionar la distribución del poder impuesta por el orden internacional en vigencia. La naturaleza revisionista de estas potencias les hace proclives a ver en las potencias mundiales y las medias un obstáculo mayor para su propio cambio de posición estructural en el sistema de poder internacional.

De las potencias regionales se esperan ciertas acciones. Suelen ejercer liderazgo regional de manera relativa, participan de la elaboración de agendas regionales, contribuyen a la solución de controversias regionales, impulsan sistemas de integración y desarrollo regionales, despliegan una política en defensa de los intereses regionales, esbozan una política exterior estratégica con potencias mundiales y apuestan por el multilateralismo. La función básica de estas potencias es la mediación, sobre todo entre potencias mundiales y Estados periféricos. En el esquema propuesto, China representa una anomalía taxonómica por su creciente poder económico y político y su protagonismo internacional. Ante tales circunstancias, es prudente ceñirse a la consideración de China como una potencia regional con vocación de potencia global virtual. El análisis empírico que se desarrolla en las siguientes secciones expondrá algunas de las características comentadas.

\section{EL PARROQUIALISMO DE LA PROCLIVIDAD ACUSATORIA DE TRUMP}

La conflictividad entre China y Estados Unidos procede de la política estratégica que el segundo de estos países ha conducido en el este de Asia para garantizar la supervivencia del régimen nacionalista en Taiwán tras el triunfo de los comunistas y, por supuesto, de Corea del Sur ante Corea del Norte. La "diplomacia del tenis de mesa" de Nixon inauguró una era de relaciones complejas y ambivalentes entre China y Estados Unidos que dejó atrás el antagonismo llano de las dos primeras décadas de existencia de la República Popular. En términos generales, los desencuentros más significativos durante el resto de la Guerra Fría y después de dicho periodo, con riesgo de enfrentamiento militar entre ambos países, fueron episodios de las disputas en torno al estrecho de Taiwán. En efecto, el proceso de integración económica avanzó sustantivamente desde la adopción del Acta de Relaciones Estados Unidos-China, firmada por el presidente Bill Clinton en octubre de 2000, mediante la cual el 
Congreso concedió a China la prosecución de relaciones de comercio normales permanentes. ${ }^{1}$ Este paso preparó el camino para la incorporación de China a la Organización Mundial del Comercio. Hacia 2019, el importe de comercio entre ambas economías alcanzó un monto de 559000 millones de dólares (Blazyte 2020). Este acoplamiento comercial no ha estado libre de fricciones, incluso antes de la presidencia de Trump, como lo demuestra la imposición de medidas antidumping por parte de la administración de Barack Obama en los sectores maquinaria, electrónicos, metales y minerales de China en 2013 y el subsecuente escalamiento de las disputas comerciales durante la gestión demócrata.

Trump ha tenido un discurso predominantemente negativo sobre China, al menos desde septiembre de 2011, cuando exclamó en Twitter que "China no es ni aliado ni amigo; ellos quieren pegarnos y también a nuestro país" (Trump 2011). Durante su campaña presidencial, el candidato republicano tenía bien definida su imagen de la relación bilateral, la cual repetiría reiteradamente hasta el final de su presidencia: el país asiático representa una amenaza para los intereses comerciales de Estados Unidos por el déficit comercial que se mantiene en beneficio del primero. El enfoque mercantilista del presidente, fundado en la sesgada equiparación entre el "interés nacional” y los "intereses comerciales”, está motivado en última instancia por los beneficios políticos que le ha reportado la identificación de un actor antagonista para movilizar a un electorado preponderantemente blanco, ávido de respuestas y alternativas a su desencanto con el globalismo.

Curiosamente, en enero y febrero Trump mostró un tono de aprobación sobre la estrategia de contención del virus en China en al menos 15 ocasiones (Ward 2020). El contexto que explica la inusual anuencia del presidente fue la firma del acuerdo comercial de "Fase Uno" con el país asiático, que representaba entonces una aparente salida al estancamiento en las negociaciones que se había extendido por alrededor de dos años. Una fuerza de tarea especial fue creada en Estados Unidos el 29 de enero para coordinar los esfuerzos contra la propagación del virus, pero no fue posible prevenir la transmisión comunitaria, que comenzó el 26 de febrero. A inicios de marzo surgieron voces críticas contra

\footnotetext{
${ }^{1}$ H. R. 4444 es el proyecto de ley que llevaría a la promulgación de esta ley, cuyo nombre completo es Public Law 106 286 - An act to authorize extension of nondiscriminatory treatment (normal trade relations treatment) to the People's Republic of China, and to establish a framework for relations between the United States and the People's Republic of China (U.S. Government Publishing Office S.F.).
} 
la administración del presidente Trump por el manejo de la pandemia, por lo que el mandatario comenzó a referirse al SARS-CoV-2 como el "virus chino" (Pomfret 2020). La administración debió tener buenas razones para preocuparse por desviar la atención de los medios de comunicación y el público. Después de todo, diversos pasos se habían dado para desmantelar la estructura de seguridad de la salud del país.

En su primer presupuesto, de mayo de 2017, el presidente Trump había planteado cortar en \$1 300 millones los fondos del Centro para el Control de Enfermedades (CDC). En mayo de 2018 hizo un llamado para reducir los fondos de emergencia destinados al ébola y otras enfermedades. El mismo mes, John Bolton cerró el Directorio de Seguridad de la Salud Global. Meses después, en octubre, el gobierno canceló un programa de vigilancia de virus animales conectado con el sistema de seguridad de la salud global. Un año después, el Departamento de Servicios de Salud advirtió en un reporte que el gobierno federal carecía de recursos, estaba poco preparado y coordinado para reaccionar a una pandemia de influenza. El secretario de Salud, Alex Azar, previno a Trump dos veces en enero sobre el peligro que representaba el avance del virus para el país (The Progressive Policy Institute 2020). Estas líneas permiten reflexionar sobre la aplicación concreta de la taxonomía estatal de Rocha y Morales. Sin lugar a dudas, Estados Unidos, bajo la administración de Trump, descuidó peligrosamente áreas de seguridad que nunca concibió como prioritarias. La "dirección autónoma" y "efectiva" de los asuntos internos no se cumplió en el rubro de la salud global.

El presidente y su círculo optaron por politizar la cuestión porque su preocupación fundamental era conservar el apoyo político de sus votantes en año electoral. Los llamados "halcones estratégicos", como Mike Pompeo, el entonces secretario de Estado; Steve Bannon, estratega en jefe, y Matthew Pottinger, asesor de seguridad nacional, hicieron eco del tono recriminatorio en contra de China por el origen del virus. ${ }^{2}$ Por otro lado, desde febrero, el senador Tom Cotton difundió la idea de que el microorganismo había sido

\footnotetext{
${ }^{2}$ Cabe mencionar que hasta la fecha hay gran incertidumbre sobre aspectos clave del origen de la pandemia. El Instituto de Virología de Wuhan, conocido por sus estudios especializados sobre coronavirus desde la crisis del SARS de 2002-3, ha identificado un virus de murciélago de herradura (rinolófido) con una compatibilidad genética del 96\% con el SARS-CoV2 en zonas relativamente lejanas a la propia ciudad. Sin embargo, los especialistas que han indagado sobre la hipótesis de un huésped intermediario que hubiese llevado el virus a la ciudad de Wuhan no han podido identificar con precisión a dicha especie. En un contexto altamente politizado sobre las investigaciones del origen de la pandemia — caracterizado además por la reticencia de China a permitir la conducción de pruebas sin restricciones de movimiento, ha venido tomando fuerza la hipótesis de un accidente de seguridad en el propio laboratorio (Regalado 2021).
} 
originado en un "superlaboratorio" en Wuhan. Tales expresiones contravinieron el llamado de la OMS a evitar declaraciones que incitaran a la discriminación racial, así como los llamados a la adopción de posturas más sensatas y proclives a la cooperación antes que al conflicto.

Es significativo que, desde enero, Pottinger haya presionado a las agencias de inteligencia del país para conseguir evidencia sobre la infundada teoría del laboratorio, suposición que contraviene los estudios científicos que apuntan hacia el origen natural del microrganismo (Saey 2020). El mismo mes, el director de la oficina encargada del rastreo de armas de destrucción masiva del Consejo de Seguridad Nacional, Anthony Ruggiero, afirmó en una videoconferencia que la CIA carecía de evidencia alguna para sustanciar alguna teoría sobre el origen del virus. Hay sectores dentro de las agencias de inteligencia que han preferido un enfoque cauto sobre la cuestión para evitar dañar las relaciones con China en el mediano y largo plazo. Además, oficiales de esas agencias remarcaron que la determinación del origen del virus es una cuestión de índole científica y no necesariamente de inteligencia. Ajeno a estas consideraciones, el presidente afirmó el 30 de abril que tenía interés en cierto trabajo de inteligencia — nunca especificado - que apoyaba la idea de que el virus había emergido accidentalmente de un laboratorio de Wuhan (Mazzetti et al. 2020). De hecho, oficiales de alto rango de la administración habían instruido un día antes a las agencias de inteligencia respecto a determinar si China y la OMS habían escondido información sobre la pandemia (Dilanian, Courtney y Lee 2020). Entre las estrategias del presidente estadunidense para vilipendiar la imagen de China estuvo la idea de demandar a ese país hasta por 10 millones de dólares por cada muerte, según reportó The New York Times (Mazzetti et al. 2020).

Un memorando estratégico del Partido Republicano filtrado en Politico dejó muy clara la racionalidad detrás de esta diplomacia de la salud de carácter ofensivo. En el documento se afirma que centrarse en China dio a los republicanos algo de qué hablar que no era el manejo de la pandemia de coronavirus por Trump (Tucker 2020). Se exhibió así la ansiedad entre algunos sectores del "Gran Viejo Partido" por mantener la unidad y, de forma indirecta, la fuerte necesidad del presidente y su círculo cercano de evadir los señalamientos sobre la ineficacia de sus acciones durante la crisis sanitaria. A nivel de partido, el líder de la 
minoría de la Cámara de Representantes, Kevin McCarthy, anunció en mayo la creación de una fuerza de tarea compuesta por 14 republicanos con el fin de investigar los orígenes del virus. La inercia política tuvo eco en otro nivel de la administración pública en el país. Eric Schmidt, el fiscal general del estado de Misuri, gobernado por el republicano Mike Parson, anunció que demandaría a China por su manejo de la pandemia (Harper 2020).

Estos procesos evidencian una tendencia muy marcada en la administración Trump por conducir la política exterior del país en función de sus intereses electorales inmediatos. Aunque la máxima de la política estadunidense de que "toda política es local" propone una dinámica de proyección particular de la coexistencia y conflicto de fuerzas internas en la conducción de las relaciones exteriores de la superpotencia, hubo una diferencia de grado en dicha administración que apuntó hacia un cambio de carácter en el comportamiento internacional del país. Así lo muestra una serie de acciones dirigidas a reforzar la estridencia nacionalista, como la salida del país de la Unesco, la amenaza de salida de la Organización Mundial del Comercio, y, de relevancia directa para el tema que ocupa este escrito, el anuncio de suspensión, el 14 de abril, del fondeo estadunidense a la OMS. ${ }^{3} \mathrm{El}$ argumento de salida fue precisamente la acusación de Trump del carácter parcial de la institución en favor de China. De esa forma, la superpotencia dio la espalda a organismos internacionales fundamentales para la arquitectura de la gobernanza global que el propio país impulsó desde el fin de la Segunda Guerra Mundial y en medio de la peor crisis sanitaria desde la pandemia de 19181919. La claudicación señala un desdén por la consideración de temas de seguridad no tradicional. La falta de voluntad de Trump para trabajar en conjunto con China sobre la pandemia está bien plasmada en el comentario siguiente: “Además de la devastación causada por el nuevo coronavirus, en EE.UU. se está extendiendo un virus político" (Redacción 2020a). La administración Trump dejó en desuso la capacidad del país para marcar líneas de acción a través de foros y organismos especializados, como propone la categoría de poder

\footnotetext{
${ }^{3}$ Debe notarse que, en agosto de 2020, la OMs había recibido $\$ 724$ millones de dólares en donaciones para la respuesta a la pandemia del coronavirus. Estados Unidos fue entonces el octavo donador, con \$34 millones, aun por encima de China, el número 10 con $\$ 25$ millones. El primero fue Reino Unido, que aportó \$108 millones. La amenaza de retiro de Estados Unidos es grave, considerando que es el principal contribuyente a su presupuesto regular, con $\$ 893$ millones de dólares aportados en 2018 y 2019. Huang Yanzhong, experto en salud global, considera que es irreal estimar que China podría llenar el vacío dejado por Estados Unidos (Lew 2020).
} 
mundial de Rocha y Morales respecto al posicionamiento institucional de las potencias mundiales.

Otro escalamiento del conflicto entre Estados Unidos y China se dio en mayo, cuando el FBI y la Agencia de Ciberseguridad e Infraestructura de Seguridad afirmaron que grupos cercanos al gobierno chino estaban intentando obtener "propiedad intelectual valiosa y datos de salud pública relativa a vacunas, tratamientos y pruebas", circunstancia que representaba “una amenaza a los esfuerzos del país por responder a la covid-19”. La acusación no fue respaldada con evidencia, pero tuvo resonancia por los procesos judiciales iniciados desde principios de 2020 contra individuos a los que se acusó de acceder y compartir conocimiento tecnológico con instituciones de China mediante programas como los Mil Talentos (Agence France-Presse 2020). A mediados de mayo, el FBI y la Agencia de Seguridad de Infraestructuras y Ciberseguridad emitieron una alerta sobre piratas informáticos que buscaban robar datos sobre salud pública y vacunas (Laborde 2020). Por su parte, el Departamento de Estado hizo un movimiento insidioso cuando filtró un "documento refutable", es decir, sin referencias ni soporte de inteligencia, al Saturday Telegraph y al Daily Telegraph en Australia, en el que sugiere que el SARS-CoV-2 procedía de un laboratorio en Wuhan (Welch 2020). El incidente generó tensión con el gobierno de Australia, que se hallaba en una situación delicada con China por la determinación del primer ministro Scott Morrison de convocar a una investigación internacional sobre el origen del virus.

En el terreno judicial, al día de hoy, fuera de la demanda de Misuri, ningún gobierno local o nacional ha demandado a China. De hecho, Trump y su círculo cercano parecen haber tenido un interés mayor en generar un ambiente de confrontación por los fines anteriormente mencionados que en judicializar efectivamente el caso. La judicialización difícilmente prosperaría porque la exigencia de reparaciones requeriría la identificación de un acto violatorio de la legalidad, y la reparación derivada sólo podría cubrir efectos directamente atribuibles al acto, mas no toda la gama de efectos asociados con la evolución de la pandemia — en la que además interviene la propia responsabilidad de otros Estados por fortalecer su preparación pandémica y ponerla en práctica de forma eficiente. Por otra parte, la judicialización rompe con el interés común que los países han mostrado desde el surgimiento 
de las primeras conferencias sanitarias en el siglo XIX por resolver diferencias derivadas de la aplicación de medidas sanitarias de manera no contenciosa (Fidler 2020).

Es importante tener en cuenta que, desde mayo de 2020, la tensión entre Estados Unidos y China por la intención de esta última de aprobar una nueva ley de seguridad en Hong Kong abrió un frente adicional de enfrentamiento entre ambos países. A su vez, las restricciones impuestas debido a la pandemia a United Airlines y Delta Airlines por la Administración de Aviación Civil de China generaron roces, al igual que las restricciones que impuso el gobierno estadunidense a las compañías que fabrican chips y semiconductores para vender sus productos a Huawei, pues requieren ahora de un permiso especial (Redacción 2020b). La reclusión de uigures en "centros de educación" en Xinjiang también ha sido motivo de tensiones en el rubro de los derechos humanos.

La disputa entre Estados Unidos y China pasó por otro momento delicado al ser arrestados dos ciudadanos chinos por el hackeo de compañías de biotecnología contratadas por el gobierno estadunidense para desarrollar una vacuna contra la covid-19. Los ataques cibernéticos se habrían dirigido a ordenadores localizados en España, Reino Unido, Alemania y Bélgica. El subdirector del FBI señaló que "este tipo de coerción económica no es lo que esperamos de un líder mundial confiable. Es lo que esperamos de un sindicato delictivo organizado" (Laborde 2020). Los ciudadanos también fueron acusados de atacar a activistas de derechos humanos en Estados Unidos, China y Hong Kong y de acceder a información sobre el diseño de armas y fármacos. En conexión con este proceso se dio la orden de cierre del consulado chino en Houston. La vocera del Departamento de Estado señaló que China estaba violando principios de la Convención de Viena sobre no intervención en asuntos internos (Redacción 2020c). La animosidad de la confrontación fue expresada con contundencia por Mike Pompeo, secretario de Estado, en una declaración hecha el 12 de agosto de 2020: "Las campañas de coerción y control del Partido Comunista de China son, al día de hoy, una amenaza más grande. El PCC está presente en nuestras economías, nuestra política, nuestras sociedades en formas en que la Unión Soviética no lo estuvo" (Ching 2020).

Al momento de escribir estas líneas, incluso con el retorno de los demócratas al poder, la confrontación entre los gobiernos de Estados Unidos y China sigue marcando el pulso de un mundo dividido y poco proclive a la cooperación. 


\section{LA RESPUESTA GLOBALISTA DE LA DIPLOMACIA DE LA SALUD CHINA}

El manejo deficiente de algunas crisis de salud en China a lo largo de este y el anterior siglo ha tenido repercusiones negativas en la imagen del país. Una de las más significativas de dichas crisis comenzó en noviembre de 2002, cuando una cepa de coronavirus desconocida con potencial pandémico emergió en Foshan, Guangdong. La infección, hoy conocida como SARS, se extendió hacia Hong Kong y Vietnam desde febrero de 2003. Esta crisis ocurrió en un momento de notable crecimiento económico y de cambio generacional en el liderazgo del país. Las medidas adoptadas para contener el SARS fueron justificadas al interior mediante una retórica de "guerra total" contra el virus. Las palabras del premier Wen Jiabao, del 13 de abril de ese año, fueron muy ilustrativas respecto al carácter total de la amenaza:

La prevención y el tratamiento efectivos de la neumonía atípica se relacionan directamente con la salud del cuerpo público y con la seguridad vital, se relacionan directamente con la estabilidad completa del proceso de reformas y apertura, y se relacionan directamente con el bienestar nacional y con la imagen internacional de nuestra nación. La nación entera debe incrementar sus esfuerzos y combatir de forma decidida y exitosa esta dura batalla contra la epidemia de neumonía atípica (Wen 2003).

El SARS pudo ser controlado hacia la tercera semana de mayo. La experiencia de esta epidemia llevó a diversos analistas a asumir que las poblaciones y gobiernos de los países afectados en el este y sudeste asiático pasaron por una curva de aprendizaje que garantizaría una respuesta eficiente cuando surgiera otra emergencia sanitaria. De hecho, el gobierno chino impulsó la promulgación de una nueva ley de enfermedades infecciosas, a la vez que implementó una reforma para el desarrollo institucional del sistema de prevención y control de enfermedades infecciosas en el país. Lamentablemente, las expectativas de una mejor respuesta no se cumplieron cuando surgieron los primeros casos de neumonía atípica, causada por otro coronavirus, en la ciudad de Wuhan, en noviembre de 2020. Las autoridades locales y provinciales reprimieron a la comunidad médica y a los medios de comunicación para evitar toda mención de la crisis sanitaria dentro y fuera de Wuhan.

El daño a la reputación de China derivado del manejo ineficiente del SARS-CoV-2 se dio en un contexto desafortunado de confrontación con Estados Unidos y de intensificación 
de los conflictos en el Mar Meridional de China. Las tensiones con Washington pueden atribuirse, precisamente, al ascenso del poderío económico, político y militar del país asiático, al cual sectores de ambos partidos en Estados Unidos perciben como un competidor indeseable en el sistema internacional. Con su Iniciativa de la Ruta y el Camino, China busca tender un puente de cooperación global que resulta útil para que se la perciba como fuente de crédito para el desarrollo, para acceder a otros mercados y para incrementar su poder político a nivel internacional. ${ }^{4}$ La iniciativa Hecho en China 2025 plantea una perspectiva de desarrollo de industrias estratégicas que empata con los objetivos de la Iniciativa de la Ruta y el Camino. Para las potencias regionales, las potencias mundiales constituyen obstáculos a su reposicionamiento sistémico (en el sentido waltziano).

La estrategia de China para reivindicar su imagen internacional por el manejo inicial deficiente del SARS-CoV-2 muestra tres áreas de influencia. La primera se centra en el desarrollo de recursos científicos y biomédicos que permitan hacer frente a la pandemia. Bastan unos cuantos ejemplos para ilustrar el punto. El 24 de enero, el director general de la OMS anunció que China había compartido con ellos y con el mundo la secuenciación genética del virus. Este trabajo aceleró el desarrollo de medios de detección y diagnóstico alrededor del mundo. Otros recursos importantes son, precisamente, el desarrollo de paquetes de detección rápida y precisa en agosto. Por último, se encuentra el desarrollo de vacunas, las cuales se consideran el medio más eficiente de generación de niveles de inmunidad suficientes como para planificar de manera segura y progresiva la reapertura de actividades. Hay cuatro vacunas chinas en un estado avanzado de desarrollo al momento de escribir estas líneas. La vacuna china más destacada es la CoronaVac, desarrollada por Sinovac Biotech a

\footnotetext{
${ }^{4}$ La Iniciativa de la Ruta y el Camino tiene el objetivo de fomentar el estrechamiento de lazos entre más de 60 países en Asia, África y Europa (que representan alrededor de 30\% del PIB global) mediante seis corredores económicos transnacionales: el Corredor Económico Terrestre de la Nueva Eurasia, el Corredor Económico China-Mongolia-Rusia, el Corredor Económico China-Península Indochina, el Corredor Económico China-Pakistán y el Corredor Económico Bangladesh-China-India-Myanmar. La iniciativa está compuesta por cinco áreas de oportunidad: coordinación de políticas (de construcción de proyectos de infraestructura), infraestructura de conectividad, comercio e inversión, integración financiera e intercambio cultural. La primera área destaca porque ha involucrado una inversión de alrededor de un billón de dólares. Fundamento importante de la iniciativa es el respaldo financiero de un fondo soberano creado ex profeso y de bancos multilaterales en cuya reciente fundación ha participado China como el Banco Asiático de Inversión en Infraestructura (AIIB, por sus siglas en inglés) y el Nuevo Banco de Desarrollo. Estos bancos, a su vez, colaboran con otros bancos multilaterales y con los grandes bancos chinos. Entre los primeros se cuentan el Banco Mundial y el Banco Europeo de Reconstrucción y Desarrollo y el Banco Asiático. Entre los objetivos estratégicos que algunos analistas estiman como parte de esta iniciativa está el acceso a fuentes de energía y la apertura de mercados para lidiar con la crisis de sobrecapacidad productiva del país (Sejko S. F.). Tal es la importancia de la iniciativa como directriz de la política exterior china que ha sido incorporada a la Constitución del país.
} 
partir de un virus SARS-CoV-2 inactivo. Las vacunas de este tipo regularmente requieren dos aplicaciones, característica que complica la logística de distribución. Sin embargo, esta vacuna pertenece a las que no requieren de una cadena de frío excepcional, entre las que se incluyen la de Oxford-AstraZeneca y la Gamaleya Sputnik V, por lo que su potencial como recurso diplomático ante países en desarrollo que no cuentan con infraestructura de cadenas de frío especiales es considerable. Aún está pendiente la publicación de resultados de los ensayos clínicos de fase 3 de la CoronaVac, conducidos en octubre en Brasil con 8870 voluntarios (Saplakoglu 2020). Otra vacuna china, la Sinopharm, que ya ha sido administrada a cerca de un millón de personas en China, será administrada en Emiratos Árabes en los próximos meses (BBC 2020b).

La segunda área de influencia es la denominada "diplomacia de las mascarillas", un enfoque de orden práctico que se apega a la idea de poder suave. Paquetes de detección, ventiladores y equipo de protección han sido enviados a cerca de 120 países (Gnanagurunathan 2020). Este tipo de diplomacia ha sido conducida con éxito en América Latina. Al menos 150000 mascarillas y trajes protectores llegaron a Brasil. Decenas de ventiladores, monitores y desfibriladores fueron enviados a Perú, mientras que Argentina recibió 10 ventiladores, 50000 paquetes de pruebas de detección y 100000 mascarillas médicas. A su vez, la Fundación Jack Ma donó 100000 mascarillas y 50000 paquetes de pruebas de detección a México. En junio, otros insumos médicos llegaron a ese país desde China. En términos generales, ha habido más de 300 transacciones relativas a la asistencia a países latinoamericanos y del Caribe por la pandemia de covid-19. La percepción entre funcionarios de los países de la región es que Beijing busca compensar su imagen internacional ante los errores iniciales en el manejo de la pandemia. Para algunos analistas, los países receptores constituyen un nuevo frente de competencia entre Estados Unidos y China, pues debe tenerse en cuenta que mientras China contribuye en especie, Washington sigue haciéndolo en efectivo a través de la Agencia de Estados Unidos para el Desarrollo Internacional, la cual aportó \$141.4 millones para dar respuesta a la covid-19 en América Latina entre marzo y agosto de 2020 (Rivers 2020).

China también ha buscado incrementar su participación de capital para la respuesta antipandémica. El 23 de abril, la vocera del Ministerio de Asuntos Exteriores, Hua Chuying, 
anunció que China otorgaría \$30 millones de dólares de fondo adicional para la OMS. En mayo, el presidente Xi Jinping se comprometió proporcionar \$2 000 millones en un plazo de dos años; sin embargo, no hubo especificaciones sobre la entrega. No debe sorprender mucho que parte de esos fondos terminen entregándose en forma de insumos. Las limitaciones relativas de orden financiero aún plantean una diferencia sustantiva en las capacidades de proyección de China respecto a Estados Unidos, por eso es difícil que en el corto plazo el país asiático sea capaz de llenar el vacío que Washington pueda dejar si se retira de las organizaciones internacionales más relevantes para el régimen de gobernanza global actual.

La tercera área de influencia en la estrategia de China es la respuesta directa a los señalamientos ofensivos de gobiernos extranjeros, marcando una ruptura con la tradición de perfil bajo afianzada en tiempos de Deng Xiaoping. De mejor manera, la actitud asertiva del liderazgo de Xi Jinping apuesta por el empoderamiento del país más que por la mera supervivencia del mismo. La premisa fundamental es la protección del interés nacional. Como en otros rubros de la política exterior, la actitud resuelta para la procuración de los objetivos de China conlleva el riesgo de una percepción del país a nivel internacional inclinada más hacia la retórica de la "amenaza china" esgrimida por funcionarios estadunidenses de principios de siglo que a la "potencia responsable" y al "crecimiento pacífico", que son parte de la retórica oficial del PCC. La defensa en los medios de comunicación y redes sociales, que puede alcanzar tonos marcadamente irónicos, es conducida por una nueva generación de diplomáticos conocidos como los "lobos guerreros". Lijian Zhao es un ejemplo destacado. Vocero del Ministerio de Asuntos Exteriores, Zhao ha sugerido que el ejército de Estados Unidos podría haber traído la epidemia a Wuhan durante los Juegos Mundiales Militares celebrados en octubre de 2019 en esa ciudad, y que ese país "nos debe una explicación" (Pomfret 2020). Otro ejemplo destacado es el del embajador chino en Países Bajos, quien hace uso de la frase "virus político" introducida por Trump:

Lo que Trump dice no tiene fundamento y está impregnado completamente por el racismo, ¡ignora totalmente el gran esfuerzo y sacrificio hecho por el pueblo chino! Éste es un virus político en contra de la solidaridad internacional y la cooperación para combatir la covid-19 (Landale 2020). 
El cambio es claramente una estrategia de Estado que puede apreciarse por el crecimiento exponencial de las cuentas oficiales de Twitter en 2020. En un tono igualmente irreverente se halla estructurado un video titulado "Érase una vez un virus", difundido por la agencia Xinhua el 29 de abril, en el que se presenta a un guerrero de Xian discutiendo con la Estatua de la Libertad; ambos están construidos con figuras de Lego. El diálogo se mofa de la inacción gubernamental estadunidense durante la etapa temprana de la pandemia.

Otro aspecto considerablemente importante en las estrategias Chinas de respuesta a las acusaciones de la administración Trump es la definición de puntos no negociables. El régimen de Xi Jinping aspira a que China sea reconocida como un actor internacional en el que convergen las características de una potencia mundial asertiva pero responsable. El trasfondo del fracaso inicial en el manejo del SARS y del VIH/sida hacen del terreno de la salud global un asunto sensible que puede vincularse a la noción de soberanía nacional, y la reputación del país es uno de los aspectos más sensibles para el liderazgo chino. Las implicaciones de una emergencia de salud mal manejada no se limitan al ámbito del bienestar de la gente y del crecimiento económico. Afectan también las relaciones exteriores del país, que está situado en una geografía políticamente compleja y, además, atraviesa un momento delicado en su relación con Estados Unidos. Los puntos no negociables son los siguientes: China no acepta que el virus surgió necesariamente en Wuhan, la falta de certidumbre en el punto anterior impide que se le atribuya una responsabilidad política por su surgimiento. Ambos puntos sustentan, a su vez, la perspectiva oficial de que la atención global debe centrarse en la cooperación antes que en la confrontación.

Los funcionarios chinos también se han preocupado por refutar de forma cotidiana y oportuna las acusaciones que funcionarios de otros países hacen en contra de China sobre su manejo de la pandemia. Baste como ejemplo la declaración de Wang Yanyi, director del Instituto de Virología de Wuhan, en la que afirmó que los virus en resguardo en esa institución no muestran la compatibilidad suficiente con el SARS-CoV-2 para determinar que este último se escapó de sus instalaciones (Kuo 2020). Las palabras del ministro de Asuntos Exteriores de China, Wang Yi, quien se refiere al manejo de la pandemia por Trump, ejemplifican la dureza de la crítica directa realizada por un alto funcionario: "No pierda más su precioso tiempo y no ignore las vidas humanas" (Tian 2020). 
Los puntos señalados permiten entender las declaraciones de Wang Yi sobre la posibilidad de abrir una investigación internacional que determine el origen del virus. Wang afirmó que su país está dispuesto a cooperar en una investigación internacional de ese tipo, pero sin injerencias políticas (Redacción 2020a). El margen de lo que resulta aceptable para Beijing respecto al impulso de esta iniciativa es reducido, como lo ha mostrado la creciente tensión entre China y Australia. Wang también ha aludido a la demanda de Misuri de manera lapidaria: "La China de hoy no es la China de hace un siglo, como tampoco lo es el mundo... Si usted quiere dañar la soberanía y la dignidad de China mediante una litigación indiscriminada y extraer el fruto del trabajo duro del pueblo chino, me temo que está usted fantaseando y sólo se humillará a sí mismo" (Tian 2020).

Aunque los errores iniciales de China en el manejo de la pandemia han dañado su reputación internacional, el vacío de poder que dejó la administración Trump en el tema de la salud global representa una oportunidad de proyección para el país asiático por su vocación mundial.

\section{CONCLUSIONES}

Dice un viejo refrán que el que se excusa se acusa. Esta máxima bien puede aplicarse para reflejar la lógica de evasión de responsabilidad interna que la administración Trump aplicó en torno a su desempeño en el manejo de la pandemia mediante la confrontación con China. Ciertamente, los errores iniciales del país asiático en la administración de la crisis condujeron a la propagación del virus fuera de sus fronteras, y esto indica una gravísima falta de aprendizaje de la experiencia del SARS en 2003. Aunque Beijing ha gastado cerca de $\$ 800$ millones para mejorar su infraestructura de prevención y control de enfermedades, todavía es ilegal que cualquier doctor comparta información sobre enfermedades infecciosas hasta que la información sea revisada y anunciada por el Ministerio de Salud (Townshend y Steward 2020). Los mecanismos de control de información siguen afectando la circulación pertinente de reportes médicos que pueden ser cruciales para responder con prontitud a un brote infeccioso con potencial pandémico en China. 
En los últimos años, los virólogos especialistas en influenza se han mostrado cada vez más escépticos a la perspectiva de poder contener un virus pandémico. Aún es necesario conocer más sobre el SARS-CoV-2 para establecer las comparaciones pertinentes. Sin embargo, es razonable plantear que podría haber situaciones en las que una respuesta asertiva de China a una Emergencia de Salud Pública de Preocupación Internacional no sea suficiente para garantizar la contención de un virus con potencial pandémico. En ese caso, la reacción asertiva del resto de los países será crucial para mitigar los efectos de un evento de esa naturaleza. Desde este enfoque, la estimación de la pandemia como uno de los más grandes fracasos en salud pública debe contemplar la responsabilidad compartida ante un fenómeno de orden sistémico. La mayoría de los gobiernos europeos, el de Estados Unidos y los de América Latina se mostraron francamente aletargados para aplicar oportunamente pertinentes medidas de contención, detección, aislamiento y tratamiento de los infectados. En el caso de Estados Unidos hay evidencia documental que confirma que diversas instancias de la administración Trump fueron informadas desde enero del surgimiento del coronavirus de Wuhan y su expansión más allá de las fronteras de China (Saletan 2020).

La determinación de la política exterior estadunidense en función de los intereses electorales de Trump fue una circunstancia particularmente grave por la consecuente erosión de las estructuras de gobernanza global en el momento preciso en que la humanidad enfrenta la peor crisis pandémica desde la gripe española de 1918 y en que, por lo tanto, se precisa urgentemente de mecanismos transversales de cooperación. Aunque China ha dado señales de comprometerse con una mayor aportación económica para el esfuerzo pandémico, no tiene aún la capacidad financiera para llenar el vacío dejado por Estados Unidos en sus contribuciones a las organizaciones internacionales relativas a la materia, sobre todo la OMS.

El nivel de compenetración de las economías estadunidense y china es suficientemente profundo como para que no se concrete su desacoplamiento por razón de las fricciones derivadas de la pandemia o incluso por la guerra comercial provocada por el presidente Trump. Entre los aspectos que mantienen esta compenetración están los índices de inversión mutua, el nivel de intercambio comercial, la inserción de China en procesos intermedios e intensivos de mano de obra de cadenas de valor internacional, la presencia de minerales raros y esenciales para la industria electrónica en China y la condición del país 
asiático de principal poseedor de bonos del gobierno estadunidense. En materia de salud, ha habido cooperación bilateral en el ámbito académico mediante intercambios y proyectos de investigación conjuntos. Respecto a la importancia de China para la salud global resalta su participación en la provisión de patógenos para organismos internacionales e institutos de investigación alrededor del mundo - un arreglo fundamental en la prevención de la influenza estacional y pandémica y del cual se benefician las compañías estadunidenses productoras de vacunas. La provisión de información científica oportuna fue importante para el avance de las investigaciones biomédicas sobre el SARS-Cov-2 en Estados Unidos.

El distanciamiento político entre ambos países, profundizado por la administración Trump, está dificultando la cooperación con China en salud pública. Tal circunstancia constituye una vulnerabilidad sustantiva ante emergencias transversales que atraviesan regiones geográficas y de desarrollo. En el país del norte hay crisis financiera y de salud pública. En el mundo hay, además, crisis geopolítica con actores como Rusia, dispuestos a difundir información sobre la pandemia que afecte la estabilidad política de sus rivales occidentales (Lissardy 2020). La producción de vacunas se ha politizado y las expectativas de cooperación entre China y Estados Unidos en este rubro son escasas en el momento actual. La mejor ruta para superar la pandemia es la cooperación entre los países, las organizaciones internacionales y el sector privado. China es un actor destacado que no puede ser dejado de lado por razones políticas y económicas y por los factores sociales determinantes de salud pública de su población. Es deseable que la administración Biden reconozca estas circunstancias y mantenga la cooperación con China en materia de vigilancia epidemiológica. Esta tarea fundamental es ineludible para hacer frente a la tendencia de creciente patogenicidad de los coronavirus. Al momento de escribir estas líneas, una cepa particularmente contagiosa se está propagando en el Reino Unido. Varios analistas apuntan que la rivalidad con China continuará siendo un eje de la política exterior estadunidense durante la presidencia de Biden; sin embargo, las líneas de cooperación fundamental sobre salud global deben mantenerse.

Conviene apreciar la fotografía completa de la crisis. En última instancia, el origen de la pandemia de covid-19 apunta a la disrupción de los ecosistemas por sobreexplotación, a la comercialización ilegal de fauna silvestre, a la conformación de espacios propicios para 
el intercambio de patógenos entre especies y a las rutas de transporte de personas y bienes que definen a la globalización. Los procesos descritos han contribuido al surgimiento de enfermedades como el ébola, el MERS, el SARS y la gripe aviar. Por otro lado, el uso excesivo de antibióticos en la agricultura está contaminando los cuerpos de agua con estas sustancias, induciendo la formación de patógenos altamente resistentes que intercambian material genético. Hoy día, hay cepas de gonorrea y tuberculosis prácticamente incurables circulando por el mundo. A esto se suma el cambio de hábitos alimenticios que propician mayores índices de sobrepeso y obesidad en países como Estados Unidos y México, con la peculiaridad característica de que la patogenicidad del SARS-Cov-2 aumenta en los individuos con mayor índice de grasa corporal. El camino de salida de esta crisis requiere esfuerzos comprehensivos y cooperación entre los distintos actores antes que confrontación.

Abraham Navarro García es profesor de tiempo completo de la Facultad de Economía y Relaciones Internacionales de la Universidad Autónoma de Baja California, con reconocimiento de Perfil Deseable del Programa de Carrera Docente y del Programa para el Desarrollo Profesional Docente. Tiene estudios de doctorado por la Universidad de Sussex y estudios de maestría por El Colegio de México, además de estudios de licenciatura en historia y derecho. Forma parte del Centro de Política de Salud Global de la Escuela de Estudios Globales de la Universidad de Sussex. Los intereses de investigación del doctor Navarro están enfocados en la política contemporánea de los países del este de Asia y en la salud global.

abraham.navarro.garcia@uabc.edu.mx

\section{REFERENCIAS}

Agence France-Presse. 2020. "US Says China Trying to Steal Covid-19 Vaccine Research." VOA News, mayo 23, 2020. https://www.voanews.com/covid-19-pandemic/us-sayschina-trying-steal-covid-19-vaccine-research 
Agencia EFE. 2020. "Costa dice que cuarentena de Reino Unido a Portugal "no tiene sentido'." El Diario, julio 6, 2020. https://www.eldiario.es/politica/costa-dice-quecuarentena-de-reino-unido-a-portugal-no-tiene-sentido_1_6085942.html

Anónimo. 2020. "Yuval Harari y el coronavirus: el gurú futurista alertó sobre los riesgos de un mundo que será completamente diferente después de la pandemia." Infobae, marzo 20, 2020. https://www.infobae.com/economia/2020/03/20/yubal-harari-y-el-coronavirus -el-guru-futurista-alerto-sobre-los-riesgos-de-un-mundo-que-sera-completamentedistinto-despues-de-la-pandemia/

BBC. 2020a. "UN General Assembly: US-China tensions flare over coronavirus.” $B B C$ News, septiembre 22, 2020. https://www.bbc.com/news/world-54253408

BBC. 2020b. "Sinovac: What do we know about China's Covid-19 vaccine?" BBC News, diciembre 10, 2020. https://www.bbc.com/news/world-asia-china-55212787

Belchi, Antoni. 2020. 'EE.UU. reclama 'transparencia' a Venezuela, Nicaragua y Cuba 'para sobrevivir a la pandemia'.” VOA Noticias, mayo 14, 2020. https://www.voanoticias. com/estadosunidos/eeuu-transparencia-venezuela-nicaragua-cuba-sobrevivirpandemia

Blazyte, Agne. 2020. "Total value of U.S. trade in goods (export and import) with China from 209 to 2019." Statista. https://www.statista.com/statistics/277679/total-valueof-us-trade-in-goods-with-china-since-2006/

Ching, Nike. 2020. “US Top Diplomat Warns of China's Global Threat.” VOA News, agosto 12, 2020. https://www.voanews.com/usa/us-top-diplomat-warns-chinas-global-threat

Deutsche Welle. 2020. “Coronavirus: China, US trade blame at UN meeting over pandemic.” Deutsche Welle, septiembre 9, 2020. https://www.dw.com/en/coronavirus-china-ustrade-blame-at-un-meeting-over-pandemic/a-55047373

Dilanian, Ken, Kube Courtney y Carol E. Lee. 2020. “Trump administration asks intelligence agencies to find out whether China, WHO hid info on coronavirus pandemic." $N B C$ News, abril 29, 2020. https://www.nbcnews.com/politics/national-security/trumpadministration-asks-intelligence-agencies-find-out-whether-china-who-n1194451 
Fidler, David. 2020. "Covid-19 and International Law: Must China Compensate Countries for the Damage?” JustSecurity, marzo 27, 2020. https://www.justsecurity.org/69394/ covid-19-and-international-law-must-china-compensate-countries-for-the-damageinternational-health-regulations/

Gnanagurunathan, A. D. 2020. "Breaking Down the China-US Tussle for Global Order Amid Covid-19." The Wire, mayo 31, 2020. https://thewire.in/diplomacy/breaking-downthe-china-us-tussle-for-global-order-amid-covid-19

Gómez, Andrés. 2020. "Filosofía y coronavirus: intelectuales chilenos confrontan la tesis de Zizek y Byung-Chul Han.” La Tercera, abril 20, 2020. https://www.latercera.com/latercera-pm/noticia/filosofia-y-coronavirus-intelectuales-chilenos-confrontan-lastesis-de-zizek-y-byung-chul-han/SSHCUMC6HVHLNAKGJRODQLU7FU/

Hall-Smith, Will. 2020. "The economic impact of coronavirus across the globe." IG Bank, agosto 10, 2020. https://www.ig.com/en-ch/news-and-trade-ideas/the-economicimpact-of-coronavirus-across-the-globe-200807

Han, Byung-Chul. 2020. "La emergencia viral y el mundo de mañana. ByungChul Han, el filósofo surcoreano que piensa desde Berlín.” El País, marzo 21, 2020. https:// elpais.com/ideas/2020-03-21/la-emergencia-viral-y-el-mundo-de-manana-byungchul-han-el-filosofo-surcoreano-que-piensa-desde-berlin.html

Harper, Justin. 2020. “Coronavirus: Missouri sues Chinese government over virus handling.” BBC News, abril 22, 2020. https://www.bbc.com/news/business-52364797

Kuo, Lily. 2020. "Global report: Wuhan lab says its bat strains were not Covid-19 as US nears 100,000 deaths." The Guardian, mayo 24, 2020. https://www.theguardian. com/world/2020/may/24/global-report-wuhan-lab-says-its-bat-strains-were-notcovid-19-as-us-nears-10000-deaths

Laborde, Antonio. 2020. "Estados Unidos acusa a 'hackers' chinos de piratear información sobre una vacuna contra el coronavirus." El País, julio 21, 2020. https://elpais. com/internacional/2020-07-21/estados-unidos-acusa-a-hackers-chinos-de-piratearinformacion-sobre-el-coronavirus.html 
Landale, James. 2020. “Coronavirus | 'Guerreros lobo', el nuevo ejército de diplomáticos que defiende a China en el mundo durante la pandemia.” $B B C$ News, mayo 16, 2020. https://www.bbc.com/mundo/noticias-internacional-52671311

Lew, Linda. 2020. "US beats China in coronavirus funding to WHO, despite threats to withdraw." South China Morning Post, agosto 7, 2020. https://www.scmp.com/ news/china/diplomacy/article/3096452/us-beats-china-coronavirus-funding-whodespite-threats

Lissardy, Gerardo. 2020. "Entrevista a Jeffrey Sachs: 'El propósito de EE.UU. es usar esta crisis para crear una Guerra Fría con China y eso es peligroso'.” BBC News, mayo 15, 2020. https://www.bbc.com/mundo/noticias-internacional-52672591

Magdaleno, Cristina. 2020. “"El sistema colapsa': Chomsky. Esta pandemia 'evidencia el fallo colosal del neoliberalismo', dice." SinEmbargo.mx, abril 21, 2020. https:// www.sinembargo.mx/21-04-2020/3771686

Martínez, Tony. 2020. "La pandemia y el sistema-mundo.” La Jornada, abril 25, 2020. https://www.jornada.com.mx/ultimas/mundo/2020/04/25/ante-lo-desconocido-lapandemia-y-el-sistema-mundo-7878.html

Mazzetti, Mark, Julian E. Barnes, Edward Wong y Adam Goldman. 2020. "Trump Officials Are Said to Press Spies to Link Virus and Wuhan Labs.” The New York Times, abril 30, 2020. https:/www.nytimes.com/2020/04/30/us/politics/trump-administrationintelligence-coronavirus-china.html

Noroozi, Ebrahim. 2020. "La pandemia agita el debate para aliviar las sanciones internacionales." El País, abril 3, 2020. https://elpais.com/internacional/2020-0403/la-pandemia-agita-el-debate-para-aliviar-las-sanciones-internacionales.html

Nye, Joseph Samuel. 2002. The paradox of American power: Why the world's only superpower can't go it alone. Oxford: Oxford University Press.

Pomfret, John. 2020. “The U.S.-China coronavirus blame game and conspiracies are getting dangerous." The Washington Post, marzo 17, 2020. https://www.washingtonpost. 
com/opinions/2020/03/17/us-china-coronavirus-blame-game-conspiracies-aregetting-dangerous/

Programa de Naciones Unidas para el Desarrollo. s. f. "Covid-19 y objetivos mundiales. Cómo una pandemia podría alterar la 'hoja de ruta' de la humanidad." PNUD. https://feature.undp.org/covid-19-and-the-sdgs/es/

Redacción. 2020a. "China y EE.UU. están 'al borde de una nueva Guerra Fría', según Pekín.” La Vanguardia, mayo 24, 2020. https://www.lavanguardia.com/internacional/ 20200524/481369539158/china-estados-unidos-guerra-fria-wang-yi-donald-trumpcoronavirus-acusacion-origen.html

Redacción. 2020b. "Estados Unidos vs China: 5 frentes de disputa entre Washington y Pekín en medio de la pandemia." BBC News, mayo 29, 2020. https:/www.bbc.com/ mundo/noticias-internacional-52815758

Redacción. 2020c. "Consulado chino en Houston: la orden de EE.UU. de cerrar la oficina diplomática de China que Pekín califica como 'una escalada sin precedentes'." $B B C$ News, julio 22, 2020. https://bbc.com/mundo/noticias-internacional-53453260

Redacción AN / ES. 2020. "Crisis de covid-19 podría generar 500 millones de pobres: Oxfam." Aristegui Noticias, abril 9, 2020. https://aristeguinoticias.com/0904/mundo/ pandemia-de-covid-19-podria-generar-500-millones-de-pobres-oxfam/

Regalado, Antonio. 2021. "No One Can Find the Animal that Gave People Covid-19." MIT Technology Review, marzo 26, 2021. https://www.technologyreview.com/2021/03/ 26/1021263/bat-covid-coronavirus-cause-origin-wuhan/

Rivers, Matt. 2020. "Pandemic power play: It's China vs. the US in Latin America." CNN, agosto 15, 2020. https://edition.cnn.com/videos/us/2020/08/14/family-compares-uschina-coronavirus-response-crn-vpx.cnn

Rocha, Alberto y Daniel Efrén Morales. 2014. "Potencias medias y potencias regionales en el sistema político internacional de Guerra Fría y pos-Guerra Fría. Propuesta de dos modelos teóricos." InterNaciones. Revista de Relaciones Internacionales 1 (1): 7-39. 
Saey, Tina Hesman. 2020. "No, the coronavirus wasn't made in a lab. A genetic analysis shows it's from nature." Science News, marzo 26, 2020. https://www.sciencenews. org/article/coronavirus-covid-19-not-human-made-lab-genetic-analysis-nature

Saletan, William. 2020. “Trump's Lies About China and the Coronavirus. A chronology of what Trump said — and what he knew - in January and February.” Slate, agosto 29, 2020. https://slate.com/news-and-politics/2020/08/trump-lies-china-coronavirus$\underline{\text { timeline.html }}$

Saplakoglu, Yasemin. 2020. "Here are the most promising coronavirus vaccine candidates out there." Livescience, septiembre 25, 2020. https://www.livescience.com/mostpromising-coronavirus-vaccine-candidates.html

Sejko, Dini. s. f. "Financing the Belt and Road Initiative: MDBs, SWFs, SOEs and the long wait for Private Investors.” Royal Melbourne Institute of Technology. https://www. $\underline{\mathrm{rmit} . e d u . a u / c o n t e n t / d a m / r m i t / d o c u m e n t s / c o l l e g e-o f-b u s i n e s s / i n d u s t r y / a p e c / a p e c-~}$ currents-dini-sejko-financing-belt-and-road-initiative.pdf

Stop TB Partnership. 2020. "The devastating effect of the Covid-19 pandemic on the TB response." Stop TB Partnership. http://www.stoptb.org/assets/documents/covid/ Covid\%20impact $\% 20$ on\%20TB\%20Modeling_Key\%20Messages_FINAL.pdf

The Progressive Policy Institute. 2020. “America’s Covid-19 debacle: A chronology.” The Progressive Policy Institute, junio 15, 2020. https://www.progressivepolicy.org/ publication/americas-covid-19-debacle-a-chronology/

Tian, Yew Lun. 2020. “China tells U.S. to stop wasting time in coronavirus battle.” Reuters, mayo 24, 2020. https://www.reuters.com/article/us-china-parliament-usa/china-tellsu-s-to-stop-wasting-time-in-coronavirus-battle-idUSKBN230076

Townshend, Ashley y Matilda Steward. 2020. "Coronavirus crisis shows both China and the US aren't equipped to lead the world." $A B C$ News, abril 19, 2020. https://www. abc.net.au/news/2020-04-19/us-and-china-step-up-their-global-health-gamecoronavirus/12157980 
Trump, Donald John. 2011. “@realDonaldTrump.” Twitter, septiembre 21, 2011. https:// twitter.com/realdonaldtrump/status/116575636583227392

Tucker, Patrick. 2020. "Covid-19 Is Accelerating Trends in the US-China Relationship." Defense One, mayo 7, 2020. https:/www.defenseone.com/policy/2020/05/covid-19accelerating-trends-us-china-relationship/165237/

U.S. Government Publishing Office. s. f. "Public Law 106-286.” U.S. Government Publishing Office. https://www.govinfo.gov/app/details/PLAW-106publ286

Ward, Myah. 2020. "15 times Trump praised China as coronavirus was spreading across the globe." Politico, abril 15, 2020. https://www.politico.com/news/2020/04/15/trumpchina-coronavirus- 188736

Welch, Dylan. 2020. “Coronavirus 'dossier' was a basic timeline of facts handed out by US State Department with no new evidence.” $A B C$ News, mayo 25, 2020. https:// www.abc.net.au/news/2020-05-26/china-coronavirus-dossier-came-out-of-us-statedepartment/12282994

Wen, Jiabao. 2003. 'Premier Wen Jiabao's speech at the National Conference on preventing and treating SARS: 'Toughen leadership, fulfill duties, and resolutely and successfully fight the tough battle against atypical pneumonia'." Chinese Law and Government 36, núm. 4 (julio-agosto): 46-57.

Wintour, Patrick. 2020. "Coronavirus: who will be winners and losers in new world order?” The Guardian, abril 11, 2020. https://www.theguardian.com/world/2020/apr/11/ coronavirus-who-will-be-winners-and-losers-in-new-world-order 